\title{
Factor Affecting User Adoption towards Internship and Career Portal in Malaysia
}

\author{
Kirubagari Vellaisamy, Ahmad Suhaimi Baharudin, Kamal Karkonasasi* and Seyed Aliakbar \\ Mousavi \\ School of Computer Sciences, Universiti Sains Malaysia (USM), 11800, Penang, Malaysia; \\ kirubagari_85@hotmail.com, asuhaimi@usm.my, asasi.kamal@gmail.com, pouyaye@gmail.com
}

\begin{abstract}
Background/Objectives: Internship is a mandatory program for all students to enable them to graduate. In other word, for most students, internship is stipulation for their graduation. Internship is intended to expose students to the real working environment and provide opportunities for students to prepare themselves for the working challenges in the future. Therefore, we intend to introduce the Internship and Career Portal to solve the problems currently affecting the existing manual system. Methods/Statistical Analysis: In order to find out the impact of user factors on the user's adoption of the Internship and Career Portal, a survey was conducted among the students that have undergone internship. A questionnaire is used to find out the factor affecting user adoption towards the portal. In this study, multiple regression analysis is applied for estimating the relationships among independent variables and dependent variable. Findings \& Results: The results of this study show that Internship and Career Pressure (ICP) and Perceived Ease Of Use (PEOU) have impact on the users' adoption of using the Internship and Career Portal. Based on the research results, the portal must consider the ICP and the PEOU to ensure that the users are satisfied with the portal.
\end{abstract}

Keywords: Internship \& Career Pressure (ICP), Internship and Career Portal, Perceived Ease of Use (PEOU), Perceived Usefulness (PEU), Trust (T), User Adoption

\section{Introduction}

The Internship Program has been introduced as a part of the curriculum for most of the higher learning institutions worldwide. Its main purpose is to expose students to a real working atmosphere and to relate their theoretical knowledge with the applications of the industry. However, many issues are currently affecting the existing manual system. Therefore, we intend to propose the Internship and Career Portal. This portal makes monitoring, instructor assignment and scheduling, grading and reporting easy. This portal is responsible in all steps of the internship process from student applications to the final grading of the student performances during the internship. This portal is developed for students all over Malaysia who are currently pursuing their tertiary studies in local universities and colleges.
The main objective of this research is to study the factors that affecting user intention to use Internship and Career Portal. Therefore, in following sections, a study has been done.

The successful use of information technologies is dependent on many factors of end-users. There has been considerable research on the factors that predict whether individuals will accept and use information portals voluntarily. The literature in user acceptance of technology identifies various theoretical models and frameworks which attempt to explain how users come to accept and use a technology. There are several models have been developed to examine the acceptance of computer technology in organizations. Among these popular models that apply in the website development are Theory of Reasoned Action (TRA), Theory of Planned Behavior (TPB) and Technology Acceptance Model (TAM) ${ }^{1}$. In fol-

${ }^{*}$ Author for correspondence 
lowing section, each model is described. Moreover, other frameworks which are proposed based on the mentioned models are stated.

\subsection{Theory of Reasoned Action (TRA)}

This theory provides a framework to study attitudes toward behaviors. According to the theory, the most important determinant of a person's behavior is behavior intent. The individual's intention to perform a behavior is a combination of attitude toward performing the behavior and subjective norm.

\subsection{Technology Acceptance Model (TAM)}

TAM is an influential extension of Ajzen and Fishbein's TRA (TRA) 2 . It was introduced and developed by Fred Davis in 1986. TAM is a model derived from a theory that addresses the issue of how users come to accept and use a technology. There are two specific variables, perceived usefulness and perceived ease of use which are hypothesized to be fundamental determinants of user acceptance ${ }^{3}$. TAM is considerably less general than TRA, designed to apply only to computer usage behavior ${ }^{4}$. But it can be readily extended to apply to any type of technology. Furthermore, it is suggested that there are external variables that affect both perceived ease of use and perceived usefulness ${ }^{5}$.

\subsection{Theory of Planned Behavior (TPB)}

TPB has also been applied in many studies to predict intention and behavior. TPB is a theory evolved from the TRA because the TRA could not fully explain behavior that is not entirely under volitional control. Attitude, subjective norm, perceived behavioral control, intention, and behavior are the five constructs in the TPB. The TPB hypothesizes that behavior is influenced by one's intention to perform the behavior and factors that may facilitate or inhibit the performance of behavior (i.e., perceived behavioral control).

\subsection{Model proposed by Zhou and Shuren Zhang}

The research model shown in Figure 1 is proposed by Toa Zhou and Shuren Zhang ${ }^{\underline{6}}$, from their research on the topic "Examining the Effect of E-commerce Website Quality on User Satisfaction". This research model analyses the effect of website quality on user satisfaction using the e-commerce website.

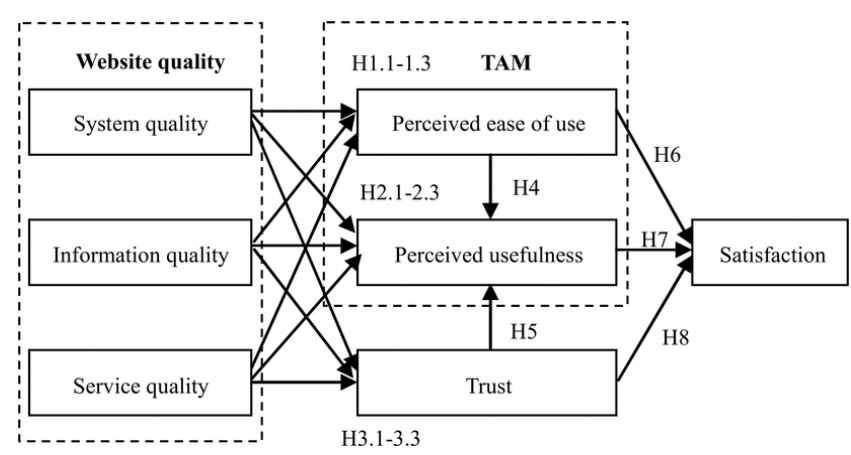

Figure 1. Examining the effect of e-commerce website quality on user satisfaction ${ }^{6}$.

The result of this study shows that the three dimensions of website quality take different effects on user satisfaction. System quality is the main factor affecting perceived ease of use, whereas information quality is the main factor affecting perceived usefulness. Service quality has no obvious effect on both factors of TAM, but has a significant effect on user trust. Researcher proposed that Satisfaction as a cumulative affect is built on the multiple interactions between user and websites. Perceived ease of use, perceived usefulness and trust will affect user satisfaction ${ }^{?}$.

\subsection{Model proposed by Chen Yu, Dong Yi- ming, Yang Bao-jian}

The research model shown in Figure 2 is proposed by Chen Yu, Dong Yi-ming ,Yang Bao-jian ${ }^{8}$. This study is about the research model and relational factors which effect individual acceptance behavior on e-recruitment $\stackrel{乛}{\text {. }}$

This research based on the TAM and integrated with subjective norm, perceived risk, perceived expense and job pressure variables to investigate what determines graduate acceptance behavior in e-recruitment. The research is almost same but research on this paper focus on internship rather than the career. The results demonstrate that perceived usefulness, perceived ease of use, subjective norm, perceived risk and job pressure all directly affect behavior intention for using E-recruitment systems ${ }^{7}$.

\subsection{Model proposed by Kia Kashi and Connie Zheng}

A study conducted among 322 job applicants in Iran? This study merges TAM and signaling theory to clarify factors affecting applicants' behavioral intentions to apply 
for jobs online. The result of this study shows that among two main constructs of TAM, only perceived usefulness has a significant influence on applicants' behavioral intentions. On the other hand, in signaling theory, impression of the organizational website seemed to create interests in organization as a potential employer. Therefore, it attracts the intention of applicants to apply for jobs. The research model shown in Figure 3.

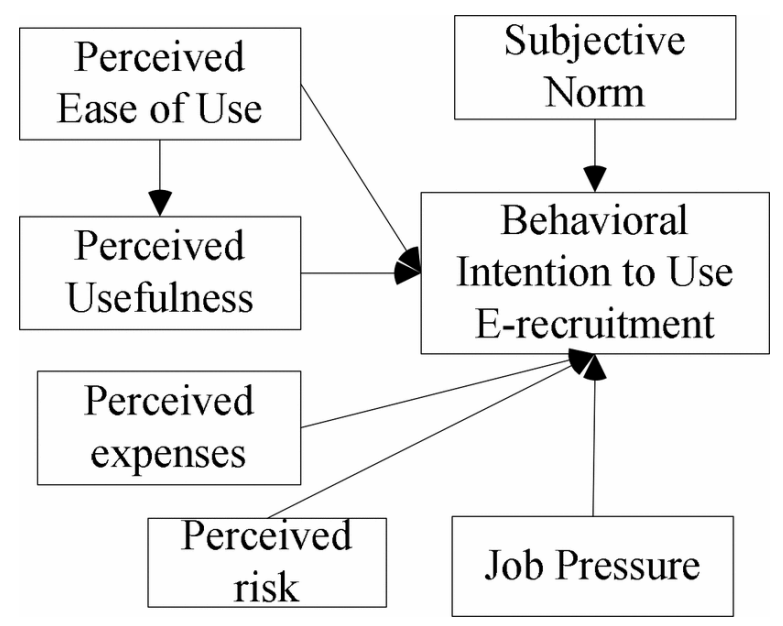

Figure 2. An empirical research on e-recruitment systems based on the technology acceptance model ${ }^{8}$.

\section{Proposed Research Model}

The proposed research model is adopted from TPB and the models proposed by other researchers [6][7][8][9]. This model consists of four independent variables which are perceived usefulness, perceived ease of use, trust and internship and career pressure.

The dependent variable is behavioral intention to use internship and carrier portal. Figure 4 shows the proposed research model in this study.

\section{Research Hypotheses}

CHEN Yu, Dong Yi-ming, Yang Bao-jian ${ }^{8}$ hypothesized that PEU positively effects on behavioral intention to use E-recruitment systems $(\beta=0.495, p<0.001)$. Similarly, PEU has direct effects on attitude behavioral intention, consistent with the study by Kia Kashi and Connie Zheng星. Therefore, this study posits that:

H1: There is a positive impact of Perceived Usefulness (PEU) on user behavioral intention to use Internship and Career Portal.

CHEN Yu, Dong Yi-ming, Yang Bao-jian ${ }^{8}$ hypothesized that PEOU has a significant positive relationship with intention to use E-recruitment portal system ( $\beta$ $=0.290, \mathrm{p}<0.001)$. This means that intention to use e-recruitment portal increased as their belief on the system ease of use increased. However, a study by Kia Kashi and Connie Zheng9 shows that no significant relationship exists among PEOU and intention to apply for jobs online. Therefore, this study posits that:

H2: There is a positive impact of Perceived Ease of Use (PEOU) on user behavioral intention to use Internship and Career Portal.

The hypothesis 3 means that students' intention to use web portal system increased as trust is increased. This

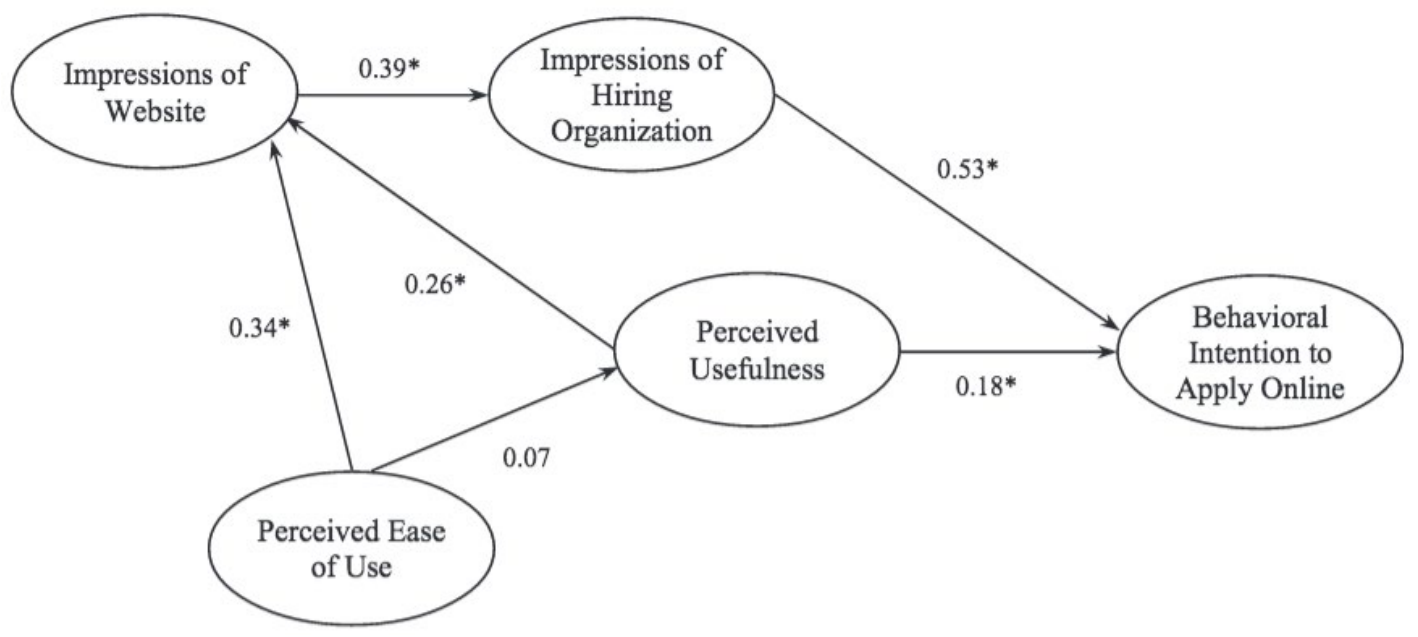

Figure 3. Extending technology acceptance model to the e-recruitment context in Iran? 


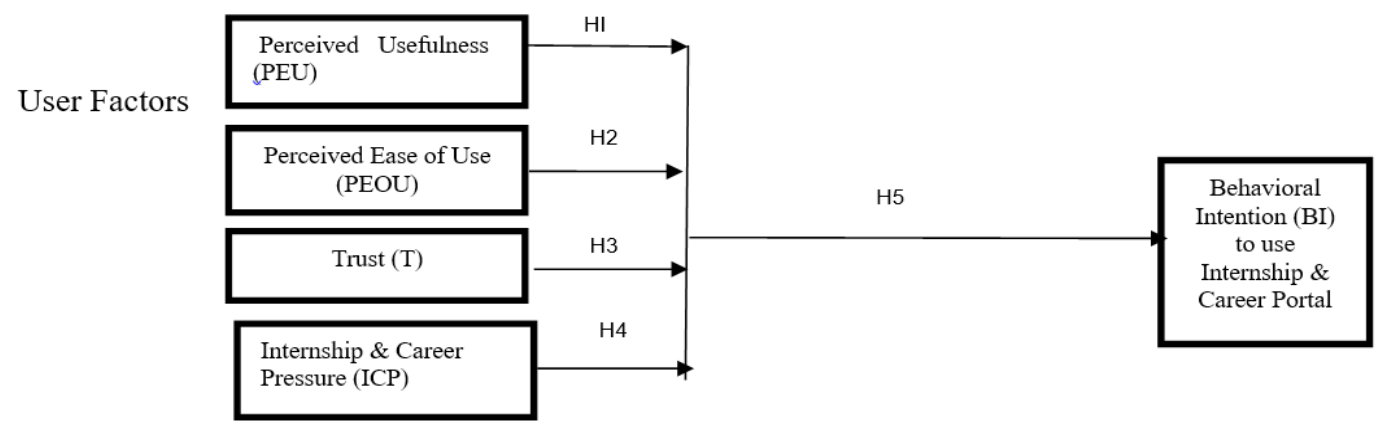

Figure 4. Proposed research model.

research also statistically confirmed that end-user trust could lead to their intention to use the system. Therefore, for the purpose of this research, it can be stated that:

H3: There is a positive impact of Trust (T) factor on user behavioral intention to use Internship and Career Portal.

CHEN Yu, Dong Yi-ming, and Yang Bao-jian ${ }^{8}$ hypothesized that job pressure (JP) has a significant positive relationship with $\mathrm{BI}(\beta=0.487, \mathrm{p}<0.001)$. The variable is modified to internship and career pressure in the current research. Therefore, this study posits that:

H4: There is a positive impact of Internship and Career Pressure (ICP) on user behavioral intention to use Internship and Career Portal.

From the four mentioned hypotheses, it stated that there is a positive impact between perceived usefulness, perceived ease of use, trust, internship and career pressure with the intention to use the portal. Therefore, this study posits that:

H5: There is a positive impact of user factors (perceived usefulness, perceived ease of use, trust, internship and career pressure) on user behavioral intention to use internship and career portal.

\section{Research Methodology}

The sample for this research was taken from the students of University Science of Malaysia (USM) School of Computer science in Penang that undergone for internship. This study develops a questionnaire to measure the validity and reliability of four constructs (perceived usefulness, perceived ease of use, trust and internship and career pressure). The items were measured on a seven- point scale ranging from ' 1 ' as 'strongly disagree' to ' 7 ' as 'strongly agree'. 150 questionnaires were distributed among respondents. However, only 102 completed questionnaires were collected.

\section{Data Analysis and Result}

\subsection{Demographic Statistic}

The majority of respondents consists of males 59\% (60 people) compared to $41 \%$ female ( 42 people). Other than that, the majority of respondents consist of Indian 39\% (39 people) followed by Chinese 32\% (32 people). The rest are Malay and other races 24\% (24 people) and 5\% (5 people) respectively.

The age groups of the respondents are between 18 to 34 years old. Most of the respondent age for this questionnaire fall between 22 to 25 (64\%, 65 people). Furthermore, a total of $58 \%$ of the respondents (59 people) had a bachelor's degree and followed by $13 \%$ (13 people) and 9\% (9 people) with masters and diplomas respectively, and for doctorate $21 \%$ ( 21 people). Internet usage by respondents that had taken part in this survey shows that as many as 7\% (7 people) have had less than a year of experience. While experience in using the Internet from 2 to 3 years are $28 \%$ ( 28 people). The period 4 until 5 years has seen as many as $16 \%$ (16 people) with Internet experience. Finally, 50\% (51 people) of respondents had experience in using the internet for as long as 5 years and above.

The frequency of E-recruitment (Job Street) that was visited by respondents for Internship and Career purpose is $85 \%$ ( 89 people). Other than that, Jenjobs with $4 \%$ (4 
people) followed by JobDB with $5 \%$ ( 5 people). $4 \%$ ( 4 people) of participants responded that they have visited other website that is not listed in the questionnaire.

\subsection{Descriptive Statistic}

It is noticed that the mean for the $\mathrm{T}$ is the highest score (5.93 of 7) among the four independent variables. However, the average score for PEU is 5.56. This score is low compared to other variables. The result shows that the respondents have intention to adopt the portal with average score of 5.63 .

\subsection{Reliability Analysis}

For the purpose of this study, reliability (Cronbach's alpha) results varied between 0.88 for PEU, 0.80 for PEOU, 0.85 for T, 0.82 for ICP, 0.87 for BI. It needs to mention that one item is dropped from ICP and BI respectively to improve reliability. Therefore, all variables are in high level of reliability.

\subsection{Correlations}

PEU ( $\mathrm{r}=0.502)$, PEOU ( $\mathrm{r}=0.613), \mathrm{T}(\mathrm{r}=0.589)$ and ICP $(\mathrm{r}=0.686)$ are strongly correlated with $\mathrm{BI}$; All correlations are significant at 0.01 level.

\section{Regression Analysis}

\subsection{Simple Regression}

The $\mathrm{H} 1$ supported since there is a positive significant relationship between PEU and BI. There is a model with beta coefficient 0.502 . And from R Square value, it can be concluded that at least $25 \%$ of the variation in the dependent variable can be explained by variation in the independent variable.

The $\mathrm{H} 2$ supported since there is positive significant relationship between PEOU and BI. There is a model with beta coefficient 0.613. And from R Square value, it can be concluded that at least $37 \%$ of the variation in the dependent variable can be explained by variation in the independent variable.

The H3 supported since there is relationship between $\mathrm{T}$ and BI. There is model with beta coefficient 0.589 . And from R Square values, it can be concluded that at least $47 \%$ of the variation in the dependent variable can be explained by variation in the independent variable.
The H4 supported since there is relationship between ICP and BI. There is a model with beta coefficient 0.686 . And from $\mathrm{R}$ Square values, it can be concluded that at least $34 \%$ of the variation in the dependent variable can be explained by variation in the independent variable.

\subsection{Multiple Regressions}

The proposed research model is significant $(\mathrm{p}<0.01) .53 .1$ $\%$ of variance in the dependent variable is explained by the independent variables. $\mathrm{BI}$ has the strongest relationship with ICP $(\beta=0.422)$ and PEOU $(\beta=0.288)$ respectively. However, there is not any significant relationship between $\mathrm{BI}$ with PU and T respectively.

\section{Discussion}

Based on the data analysis, this research emphasizes the use of the two factors (ICP and PEOU) in designing the Internship and Career Portal to increase the students intention towards the portal. The respondents are not concerned about the personal information that is shared with the portal because they can decide which parts of the information they consider to disclose. Therefore, $\mathrm{T}$ is not a predictor for BI. Previous study indicated that PEOU has significant impact on BI, if aim system is novel for end users. Therefore, PEOU positively influences on BI to use Internship and Career Portal. There is not any significant relationship between PEU and BI. This result is inconsistent with many previous studies. The main reason can be that the students cannot obtain the favor internship programs among companies using the Portal. Therefore, we need to improve the portal to increase its usefulness. There is positive relationship between ICP and $\mathrm{BI}$. The reason is that competitive employment environment cause students to use effective tools to get a place for internship.

\section{Conclusion}

This paper provides a new outline for the evaluation of internship and career portal. This portal is introduced to overcome and enlighten student task when applying for internship and career. In short, it is a system that replaces current manual process. In addition to that, companies and the public and private institutions benefit from this portal. It also makes the internship and career process smoother. A survey has been conducted among the 
students that undergone internship to find out user adoption's factors. The survey result shows that the student will use the portal if the portal considers perceived ease of use as a factor for development. Moreover, if the portal can reduce students' internship and career pressure then it can increase their behavioural intention to adopt the system.

\section{Acknowledgement}

KV would like to thank Universiti Sains Malaysia (USM) as this research has been supported from the Research University Grant (RUI) [Account Number: 1001/ PKOMP/811251] and from Incentive Graduate on Time (GOT) Grant [Account Number: 1001/PKOMP/823131] from the Universiti Sains Malaysia.

\section{References}

1. Riedel R, Fransoo JC, Wiers VCS. Modelling dynamics in decision support portals. Proceedings IEA Congress. Piekaar RN, Koningsveld EAP, Settels PJM, editors, (CD-ROM); 2006.

2. Ajzen I. From intentions to actions: A theory of planned behavior. Action Control. 1985:11-39.
3. Venkatesh V, Davis FD. A model of the antecedents of perceived ease of use: Development and test. Decision Sciences. 1996; 27(3):451-81. Crossref

4. Davis FD, Venkatesh V. Toward preprototype user acceptance testing of new information portals: Implications for software project management. IEEE Transactions on Engineering Management. 2004; 51(1):31-46. Crossref

5. Davis FD, Bagozzi RP, Warshaw R. User acceptance of computer technology. A comparison of two theoretical models. Management Science. 1989; 35(8):982-1003. Crossref

6. Zhou T, Zhang S. Examining the effect of e-commerce website quality on user satisfaction. Second International Symposium on Electronic Commerce and Security, ISECS'09; 2009 May. p. 418-21. Crossref

7. Yu C, Bao-jian Y, Yi-ming D. Empirical study of individual acceptance behaviors in E-recruitment system. 4th International Conference on Wireless Communications, Networking and Mobile Computing, WiCOM, Dalian; 2008. p. 1-5.

8. Yu C, Yi-ming D, Bao-jian Y. An empirical research on E-recruitment systems base on the technology acceptance model. 6th International Conference on Service Systems and Service Management, ICSSSM'09, Xiamen; 2009. p. 429-33.

9. Kashi K, Zheng C. Extending technology acceptance model to the e-recruitment context in Iran. International Journal of Selection and Assessment. 2015; 21(1):121-9. Crossref 